\title{
Navigation Tools and Equipment and How They Have Improved Aviation Safety
}

\author{
Sulaiman D. S Alsahli ${ }^{(1)}$, Fadala Hassan ALfadala ${ }^{(2)}$
}

\begin{abstract}
This paper highlights the impact of navigation tools and equipment, such as the GPS, navigation radar, and other communications tools, which aid in ensuring aviation safety. It emphasizes the need for aviation safety and how these navigation methods are of great help to reduce the hazards and clearly indicate the problems related to the aircraft, aircraft traffic management, weather disturbances, among others. It also recommends how these tools and equipment must be further developed to promote more safety in aircraft flying.
\end{abstract}

Keywords: Aviation safety, GPS, GNSS, navigation equipment, navigation tools, weather disturbance, general aviation, civil aviation

\section{INTRODUCTION}

The concept of aviation safety is expansive, and it includes the fundamentals, investigation, and classification of flight failures, and how these failures can be prevented through further training, learning, and regulation (Caldwell \& Mallis, p. 1). Aviation safety is also a loose concept that is used in educating the public on the safe air travel (p. 1). Aviation safety is paramount since fatal accidents have occurred every ten years since the 1950's (Collins, p. 1). It has coincided with the massive growth of air travel since that period. To cite, there were about 40 fatal accidents per one million airplane departures in the United States in 1959 (p. 1). After one decade, this has been reduced into less than 2 in every one million air trips. These achievements have further improved into a drop of around 0.1 percent in the same range (p. 1).

Aviation safety improvements became even more impressive when air traffic increase is taken into account. According to the InternationalAir Transport Association (IATA), global airlines flew about 3.3 billion passengers with only 12 fatal accidents and 641 fatalities (p. 1). In short, aviation safety has greatly improved with these historic rates of reduction in fatalities. The global jet accident rate in 2014 was 0.23 percent, and this equated to about one accident for every 4.4 million flights (p. 2).This was a modest improvement since the global hull loss rate was 0.41 percent in the previous year (p. 2). This translated into about one accident every $2.4 \mathrm{~m}$ flights (p. 2). Both the figures in 2013 and 2014 showed large development from the five-year rate (2009-2013) of 0.58 hull loss accidents per one million flights (p. 2). Five decades back, when airlines only carried 141 million passengers, about
87 plane crashes occurred (p. 2). It amounted to about 1,597 fatalities (p. 2).

The huge improvement in aviation safety can be very well attributed to engineering excellence, a combination of various factors such as the introduction of jet engines (p. 1). As reported, the use of jet engines gave an unprecedented level of safety and reliability compared to the piston engines (p. 1). Presently, the manufacturing of airplane engines today have almost zero chance of engine failures (p. 1). Other major factor is the introduction of electronics, such as the use of digital instruments called the "glass cockpit" (p. 1). This was initially used during the 1970s. Another significant development which improved aviation safety was the advent of fly-bywire technology in the 1980s (p. 1). Lastly, the refinements in navigation equipment and tools, sensors, and air traffic control technology, like the anti-collision control systems, have also greatly impacted aviation safety (p. 1). This paper shall focus on the contributions or effects of navigation tools and equipment and navigation methods or technology, as a whole, in the overall reduction of airline accidents and fatalities. This shall emphasize the crucial role of navigation technology in ensuring aviation safety. Many navigation tools exist today, and they help assist with weather, collision avoidance, automatic flight control and recording, flight management, public address, and entertainment systems, etc.

\section{Navigation Tools and Equipment and How They Have Improved Aviation Safety}

A major navigation tool which has changed the ways of aviation is no less than the GPS or the "global positioning system" (Chakrabarty, p. 1). This system is space-assisted, and it has been a very indispensable tool for any 
air, land or marine navigation. Newer or more advanced control systems that provide greater accuracy and integrity to the GPS are also conducive to the further development of aviation safety (p. 1).In the past, pilots often relied on nautical charts that were plotted on papers and were the official database of the government authorized hydrographic agencies (p. 1). Those charts were actually used to provide a two-dimensional setting of the sea or river banks and its general topography in order to ensure safe navigation. Navigational charts were also used to know navigational hazards, instant elevations on the sea bed, damages which hinder the navigation channel in restricted water, any type of local man-made establishments, bridge positions, ports, physical structures on the shore, position of the guiding buoys, turrets, obelisks and other seashore indicators (p. 1). These charts were usually prepared by the hydrographic departments and were refreshed after specific gaps, hence, making navigation vulnerable to instant changes on the sea bed of the channel (p. 1). These charts were also cumbersome since they used a large space in the chart room on the bridge where charts were posted. This has been replaced by the Electronic Nautical Charts (ENCs) (p. 1).

There are two classifications of the ENCs, the raster and the vector chart (p. 1). The former is a basic scanned type of the navigational charts, and the latter is the more data-driven. While they are not seen, the data at a certain position are automatically shown when clicked (p.1). Navigational software such as the ECDIS or the Electronic Chart Display Information System enhances the ENC through customization (p. 1). These ENCs follow the guidelines of International Hydrographic Organization. Likewise, these charts are periodically updated based on the IMO adopted resolution inviting governments of member countries to render their respective hydrographic surveys and publish and disseminate nautical data for safe navigation (p. 1). These member governments are also mandated to regularly update their data and share their information to all, to ensure the widest uniformity in the published charts.

At present, the GPS is linked into more than 190,000 general aviation aircraft in the United States alone; it is included in more than 80 percent of the U.S. fleet (GPS Alliance Website, p. 1). Most of these American aircrafts rely on the GPS mainly for navigation. More than its use in the commercial aviation, GPS is also heavily utilized in military and other types of aircrafts which enter the U.S. airspace (p. 1).Basically, GPS provides pilots with a dependable and accurate navigation source (p. 1). It gives them the ability to fly pointto-point instead of routing via ground-based radio navigation which needs longer flight paths between airports (p. 1). As integrated with maps, GPS enables pilots to instantly orient their aircraft relative to their flight path, terrain, obstacles, and weather (p. 1). This significant safety benefits lessen the workload of the pilot and free them to focus on flying the airplane instead of staying on course. This technology is also very important during in-flight emergencies when there is a need to urgently know the next nearest emergency landing (p. 1).

In recent aviation history, the use of GPS in advanced Terrain Awareness and Warning Systems (TAWS) has been acknowledged. According to the FAA, fatal controlled-flight-intoterrain (CFIT) accidents in general aviation from 2006 to 2011 slumped into a 44 percent decrease compared to the previous five years (2000 to 2005) (p. 1). Also, non-scheduled air carrier operations decreased by 44 percent from the previous duration. There was also a 30 percent decrease in the fatal approach-and-landing accidents and all fatal nighttime accidents (p. 1). For U.S. airliners, the use of GPS-enabled TAWS systems has totally lessened CFIT accidents.GPS also enables aircrafts to land safely; it requires a substantially less ground infrastructure than systems or procedures based on ground-based navigation systems. Hence, the technology increases the total number of airports with instrument approaches while it also reduces its costs (p. 1). As enhanced by the FAA's Wide Area Augmentation System (WAAS), GPS supplies both horizontal and vertical guide that balances approaches to a safe landing (p. 1). GPS is the only instrument approach that can be used in various locations, with more than 900 of the roughly 3,000 airports and heliports in the U.S. and its territories having only GPS-based approaches (p. 1). All these go to show the many advances of the GPS as a navigation technology that significantly enhances aviation safety. GPS also features environmental and economic benefits such as shorter flight paths, less fuel burn, lower costs, and smaller carbon footprint (p. 1).

The Airport Surface Detection Equipment$\mathrm{X}$ networks data from an inbound plane's GPS unit and the transponder signals from ground vehicles and other planes in the air to obtain a continuously updated map of all airport traffic. Remote towers gather and relay information from airplanes in flight. ASDE-X, which alerts air traffic controllers to an impending conflict, is already in use at 20 U.S. airports since 2011 (Wise, p. 1). Other technological improvements include the use of digital maps of airports and the nearby areas that are very flexible to amend to accommodate new infrastructures and physical hindrances (p. 1). Pilots now carry laptop-size computers called 
Electronic Flight Bags which are plugged into the cockpit's navigation system. New EFBs alert users to update maps through Wi-Fi. There are also detectors which utilize sensitive radar with wavelengths as tight as a millimeter to determine the smallest debris as a bolt which could cause an air crash. Global navigation satellite system (GNSS) is also extensively used for aviation safety. Pilots operating under the VFR may use GNSS to aid in map reading and other visual navigation techniques (Civil Aviation Safety Authority, p. 5). However, GNSS must not be taken to replace visualnavigation techniques as this is the main cause for the increasing number of violations ofcontrolled and restricted airspace by VFR aircraft. GNSS may be used as a night VFR navigation aid. The mandated use of the GNSS in Australia includes the following applications: DR substitute; IFR RNAV; RNAV (GNSS) nonprecision approach; Oceanic RNAV; and GNSS landing system (GLS). The usual GNSS practice is to:plan the route with the use of charts; put the plan into the GNSS unit or retrieve a saved plan from volatilememory; check the information in the GNSSdatabase and the user waypoint information against charts or a flight plan that has waypoint names, identifiers, latitude/longitude, tracks and distances (p. 7). Advanced weather monitoring systems also combine GPS systems forprecision navigation with distinct computer-generated topographic maps (Ochieng, et. al., p. 2). This view is the same as a flight view under visual meteorological conditions or a "synthetic vision." It illustrates the use of the latest navigation technologies that reduces aircraft accidents.Satellite-based precision navigation also enhances the abilityof aircraft to perform allweather landings (p. 2). The Airborne Information for Lateral Spacing (AILS) systemmonitors the distance between aircraft entering parallel runways with the use of a ground-based differential GPS devices. AILS enables aircraft tosafely operate in closer proximity as they approach parallel runways (p. 2).

NASA also pioneers a system called Taxi Navigation andSituational Awareness (T-NASA) that greatly speed upaircraft movement to and from terminal gates (p. 2). T-NASA sends taxiinstructions to the pilot's computer and provides a moving image of theaircraft and other traffic near it. The said system enables pilots to safely taxi at higher speeds, even at night and during times where there is low visibility (p. 2). Efficient landing certainly increases aviation safety and security.A related system called "Roll Out and Turn Off" shows information to the pilot to make full use of braking distance (p. 2). This aids in reducing an aircraft's time on the runway. Ground controllers are also able to monitor the location and movement of aircraft moving to and from gates (p. 2). As reported, the FAA and NASA are jointly developing a "Surface MovementAdvisor," that combines airline schedules, gate information, flightplans, radar data, and runway configurations to help ground controllersbetter control the movements of arriving and departing aircraft (p. 2).Other new systems are crafted to avoid conflicts in low-visibility settings. One example is the NASA's DynamicRunway Occupancy Measurement (DROM) system (p. 2). This system indicates the spacing of landing aircraft, hence, reducing the traffic and accidents in the runways. It predicts the time by which a given type of aircraft will land and clear a runway and then pass the information to other flight planning systems (p. 2).

Another navigation tool is a handy chart plotting software or the SEA CLARE (p. 1). It is a PC-based software for Windows 2000 and above (p. 1). When linked to the GPS, it depicts present position, speed and heading of the aircraft in real time. New charts can be automatically looped into the text file, and tracks can be saved for later review. Pilots can manually update and enter entries. To assist navigation, this software allows varied waypoints. However, the GPS transmission capability must be of a further updated version called NMEA 0183 (p. 1).Pilots also make heavy use of the navigation instrument called the RADAR fitted with ARPA (p. 1). Radar or a radio detection and ranging device, which is capable of reflecting electromagnetic wave, is heavily useful to ensure safety in both air and marine travel (p. 1). This is because all aircrafts, ships, structures such as buildings, vehicles, landscapes, waterscapes, etc. reflect radio waves. It makes them all visible on the screen (p. 1). This ARPA can compute the speed of the tracked aircraft, its course, among others (p. 1). It can also forecast the closest point of approach. Relative speed between the aircraft and a static point like a land mass can be computed and collision point and time are all indicated. Upgraded and more integrated ARPA has replaced the former stand-alone unit.Another navigation tool called Pilot Mate, which was produced by a Norwegian company, Maris, instantly integrates the bridge gadgets (p. 1). This tool relies on a different chart based system on ECDIS (p. 1). It also features history, real color display of ENC buoys, route plans and monitoring aside from its real-time updates and tidal information, both of which can be sent via e-mail (p. 1). This navigation tool greatly reduces human errors since it indicates all the specific details in a digital setting. 


\section{CONCLUSION}

Aviation is critical to each country's economic success and security. In the United States alone, 2009 figures indicated that civil aviation generated US\$1.3 trillion annually to the national income (GPS Alliance Website, p. 1). It has also added about 5.2 percent tothe gross domestic product (GDP) and brought in more than 10 million jobs, with a US\$397 billion income (p. 1).The general aviation sector alone contributes at least US $\$ 150$ billion to the U.S. economy every year, and it supports over 1.2 million jobs and gives crucial air services to each community in the United States (p. 1).

In this line, aviation safety is very significant to economic development. Hence, the need for better navigation systems and equipment and tools is also necessary. It serves as the answer to the need for a systemic approach to fulfilling the requirement for the use of modern equipment, such as those navigation tools described above. A major breakthrough is the use of the GPS and this shall, even more, multiply into further innovations integrating the ground, air and sea detailed maps and estimations.To conclude, navigation technology serves as a foundation for a safe and secured global aircraft operation activity. There is a need to improve the safety performance indicators for the total aviation system. Such safetyperformance indicators are mostly reliant on the navigation tools for efficiently and cost reduction. Hence, the further research and development of navigation technology is a major key to enhancing the safety of aviation.

\section{RECOMMENDATIONS}

The most urgent challenge in present-day aviation is to be able to fulfill the need for increased capacity while simultaneously decreasing the prospect of aircraft fatality. In the next few years, commercial aircraft industry must be able to combine technologies to achieve this goal. Hence, it is paramount that the global aircraft industry is updated with modernization initiatives, specifically in navigation systems and tools. It is also a great opportunity to reshape the equipment and tools to reduce future accidents better. Many of the newtechnologies should introduce better cockpit systems which upgrades the automation level and computer-based systems reliance (Ochieng, et. al., p. 2). Other recommendations would be those that improves the aircraft architecture, such as introducing basic shifts in aircraft control, predicting the weather, and enhancing aspects of air communications.

Plans on modernization should also cover each phase of aircraftoperations, materially changing equipment, operational procedures, andthe means by which the aircraft derives data for diagnosing what occurs in an aircraft mishap. Most research delves into further improving capacity focuses on three major aspects:

- enhancing the ability to fly in all types of weather and with higher air traffic densities;

- $\quad$ using airspace more efficiently;

- quick processing of aircrafts through and around terminal areas.

Aviation safety has been threatened by weather conditions for so long (p. 2). The greatest threat comes from the pilot's reduced visibility. Many aircraft accidents are linked to the weather. Hence, in the future, pilots should be able to overcome this through the use of advanced navigation technology to "see beyond the weather" (p. 2). This ability, integrated with methods for clear-air turbulence and other weather condition predictions, would provide the air crews and ground controllers a fuller map to steer ahead.

This proliferation of newer navigation technology crafted to meet thepressing demands

of further aviation safety and performance may also integrate the introduction of new safety threats into the commercial aviation industry. As the pilot's use of the GPS has shown, it also carries some negative performance such as over-reliance of the pilot for satellite-based navigation. Proper knowledge and training are very critical.

\section{WORKS CITED}

[1]. "Aviation and GPS."GPS Alliance Website, http://www. gpsalliance. org/ aviation. aspx.*

[2]. Caldwell, J. \&Mallis, M. "Fatigue Countermeasures in Aviation."Aviation, Space, and Environmental Medicine. 80 (1): 29-59.

[3]. Chakrabarty, A. "Marine Navigation." Marine Insight, http://www. marineinsight.com/marine-navigation/ marine-navigation-systems-andelectronic-tools-used-by-ships-pilot/.*

[4]. "Global Navigation Satellite Systems." Civil Aviation Safety Authority, https://www.caa.govt.nz/safety_info/semi nars/Flt_Examiner_Seminar_2008/GNSS_ Pilots_Guide.pdf.*

[5]. Ochieng, W., et. al. "GPS Integrity and Potential Impact on Aviation Safety." The Journal on Navigation, DOI: https:// doi.org/10.1017/S0373463302002096.

[6]. Wise, J. "The Tech that Makes New Airplanes and Runways Safer." Popular MechanicsWebsite,http://www.popularme chanics.com/flight/a5013/4338852/.*

[7]. "Human Error." Boeing Aero Magazine, http://www.boeing.com/commercial/ 
aeromagazine/aero_08/human_textonly.ht $\mathrm{ml}$ *

[8]. International Civil Aviation Organization. Human Factors in Civil Aviation Security Operations. ICAO, http://www. eamac.ne /Doc/Normes/OACI/Doc\%20et\%20Manu els/OACI_9808_en-Facteurs\% 20humains.pdf.*

[9]. Sputnik International. Blunders that Burned Brussels: Belgium's Six Main
Security Failures. Sputnik, https:// sputniknews.com/europe/2016032410368 74532-brussels-terror-attacks-security/."

[10]. Walt, V. "Belgium's Security Failures Made the Brussels Attacks All But Inevitable." Time Magazine Online, http://time.com/4269505/brussels-attackssecurity-failure-belgium/.* 